\title{
Effects of Patient Education Program on the Quality of Nursing Care and Inpatient Satisfaction in Surgical Wards of Selected Hospitals in Isfahan, Iran
}

\author{
Shahnaz Keifi ${ }^{1}$, Mohsen Shahriari ${ }^{2}$, Zahra Baghersad ${ }^{2}$, Donya Sheibani-Tehrani ${ }^{3}$, Farzaneh Rejalian ${ }^{4 *}$ \\ 'Imam Khomeini Falavarjan Hospital, Isfahan, Iran \\ ${ }^{2}$ Nursing and Midwifery school, Isfahan University of Medical Sciences, Iran \\ ${ }^{3}$ Shahid Beheshti University, Tehran, Iran \\ ${ }^{4}$ Department of Health Services Management, Health School, Yazd University of Medical Sciences, Yazd, Iran
}

"Corresponding Author: Farzaneh Rejalian, Master of Health Services Management, Department of Health Services Management, Health School, Yazd University of Medical Sciences, Yazd, Iran. Tell: 09132111608; Email: f_rejalian@yahoo.com

Received August 10, 2016; Accepted October 5, 2016; Online Published December 18, 2016

\begin{abstract}
Background: The implementation of patient education within a hospital is a difficult task that plays a key role in improving and controlling diseases and providing quality healthcare services.

Objective: The current study evaluated the effect of patient education on the quality of nursing care and inpatient satisfaction in surgical wards of selected hospitals in Isfahan, Iran.

Methods: This quasi-experimental study was conducted in 2014. The sample group consisted of 64 patients admitted to the surgical wards of select hospitals in Isfahan and selected using the voluntary sampling method. Participants were randomly divided into experimental $(n=32)$ and control $(n=32)$ groups. A patient education program was implemented for each subject in the experimental group (during hospitalization and after discharge), but no intervention was conducted for the control group. Data was collected from both groups before and after the educational intervention using the standard questionnaire SERVQUAL to measure expectations (with a reliability of $87 \%$ ), perceptions (with a reliability of $85 \%$ ), and inpatient satisfaction (with a reliability of $83 \%$ ). Data was analyzed using descriptive statistics, univariate and multivariate analysis of covariance, Kolmogorov-Smirnov, chi-square, and $t$ tests in SPSS software.

Results: The results of covariance analysis showed that the patient education program significantly increased the mean scores of the quality of nursing services and inpatient satisfaction in the experimental group compared with the control group $(P<.01)$.

Conclusion: A patient education program is an important pillar for improving public health. It is also a low-cost intervention to increase a patient's hope in living a good quality life.

Keywords: Patient education, Quality of nursing care, Patient satisfaction, Surgical wards
\end{abstract}

\section{Background}

Education on health issues is necessary for a patient's physical and mental health. ${ }^{1}$ Everybody finds themselves in situations where they require special knowledge and skills in order to meet their basic needs and sustain their lives. One such situation relates to loss of health and hospitalization. ${ }^{2,3}$

All patients have the right to be educated on maintaining their health, disease prevention, and health promotion. ${ }^{4}$ Health promotion is the process of advancing knowledge, influencing attitudes, and determining relevant solutions so that people can make informed choices, change their behavior, and subsequently attain a desirable level of physical and mental health and improve their social and physical environment. ${ }^{5}$
The concept of patient education is shaped and considered as a key role of nurses in the provision of health services. ${ }^{6}$ Education increases a patient's ability for selfcare and results in improved health and the prevention of disease. ${ }^{6}$ Patient education is considered an important identity and principle in healthcare services, ${ }^{7}$ a criterion for securing patient's hospital rights, ${ }^{8}$ a means to achieve health promotion, and a combination of educational activities planned to help people who are experiencing a disease or its complications. ${ }^{9}$ Patient education must be done regularly and continuously at various interconnected levels to obtain the desired outcome. ${ }^{4}$ Moreover, patient education programs are dynamic and interesting processes to improve, maintain, and enhance patient care $\mathrm{e}^{10}$; this is a patient-driven process based on the needs expressed

Copyright $\odot 2016$ The Hospital Practices and Research. This is an open-access article distributed under the terms of the Creative Commons Attribution License (http://creativecommons.org/licenses/by/4.0), which permits unrestricted use, distribution, and reproduction in any medium, provided the original work is properly cited. 
by patients and physicians to help the patient make participatory and informed decisions concerning his disease. $^{8}$

In recent years, the role of nurses as the most pivotal member of the healthcare team has undergone a historic transformation. ${ }^{11}$ Nurses make up over $70 \%$ of the healthcare team. They have greater access to the patient and his/her family and spend a lot of time giving patient care; therefore, nurses provide frequent opportunities for training to patients and are able to evaluate the quality of education. ${ }^{3}$

Service delivery starts at admission and continues until discharge. ${ }^{12}$ The surgical ward is one department in the hospital where patients and their relatives spend different amounts of time on care and treatment.

Hakari and Mohammadzadeh conducted a study in Tabriz and referred to the following factors as patient education barriers: large numbers of patients, nurses' lack of time, lack of personnel, lack of teaching aids, lack of cooperation and coordination between the various members of the health team, lack of devotion of specified time to patient education, nurses' unwillingness to perform training, nursing managers' lack of support, and nurses' lack of awareness regarding patient education materials. ${ }^{13}$ Bahrampour and Zolala stated that patient satisfaction during the care process is achieved when there is homogeneity and agreement between the patient's expectations of received care and the education and care services given based on the patient's physical, mental, and social needs. ${ }^{14}$ In another study, Nouhi and Pooraboly stated that nurses' performance in patient education is undesirable and low quality. ${ }^{15}$ Taylor suggested that patient education programs along with nurse education programs can reduce damage resulting from disease in patients. ${ }^{16}$ Zimmer et al stated that the level of knowledge of nurses has increased significantly in recent years. In addition to providing the necessary training for nurses, patients' self-efficacy is also significantly increased commensurate with the increase in information, which increases patient satisfaction with services. ${ }^{17}$ In a systematic study, Du et al stated that patient education programs can be useful as potentially safe methods to reduce injury caused by disease and to increase patient satisfaction with the quality of services provided. ${ }^{18}$ Coates et al stated that patients need to be educated on activities such as sports, health, sleep, nutrition, rest, and relaxation. ${ }^{19}$

\section{Objective}

The current study, conducted in 2014, aimed to determine the effect of patient education programs on the quality of nursing care and inpatient satisfaction with surgical wards in selected hospitals of Isfahan. It was hypothesized that patient education has an impact on improving the quality of nursing care and increasing inpatient satisfaction in surgical wards.

\section{Methods}

This study was a quasi-experimental design with experimental and control groups. Pre-tests and post- tests were conducted. Subjects were randomly divided into experimental and control groups. The pre-test was administered before implementing the empirical intervention, and the post-test was conducted at the end of the intervention. Considering the nature and purpose of this 2014 study, the patient education program (independent variable) was applied by nurses to determine its effect on patients' perceptions of the quality of nursing care and inpatient satisfaction in the surgical wards of the selected hospitals in Isfahan (Shahid Ayatollah Sadoughi, Sina and Ayatollah Kashani) (dependent variable).

The study population included all patients admitted to the surgical wards of the selected hospitals in Isfahan. Sixty-four participants were selected using convenience sampling and then placed into experimental $(\mathrm{n}=32)$ and control groups $(n=32)$. The sample size in the experimental and control groups were calculated using the following equation:

$$
n=\frac{2(z 1+z 2) 2 s^{2}}{d^{2}}=\frac{2(1.96+0.84) 2 s^{2}}{(0.7)^{2}}=32
$$

z1: confidence level of $95 \%$; i.e. 1.96 .

z2: $80 \%$ power factor; i.e. 1.96 .

$\mathrm{s}$ : Estimate of standard deviation of each of the variables (awareness, attitude, and performance) in both groups.

$\mathrm{d}$ : minimum mean score difference between any of the variables between the two groups that shows a statistically significant difference, and s 0.7 is considered.

In this study, several instruments were used to measure the variables of interest. A three-part researcher-made questionnaire based on the standard nativized 22-item SERVQUAL questionnaire on a 5-point Likert scale (1: Very low, 2: Low, 3: No idea, 4. High, 5: Very high) was used in this study. The first part was concerned with the personal and professional characteristics of the participant, including age, sex, marital status, education, and clinical work experience. The second part assessed the quality of nursing care in the five dimensions of tangibility, reliability, responsiveness, assurance, and empathy and patients' expectations and perceptions regarding services. Scores ranged from 22 to 110 . On this questionnaire, score gaps were calculated based on the difference between the two sets of questions related to patients' expectations and perceptions. A negative score indicated that the quality of the actual service (perception score) was lower than the expected limit (expectations score). The score gap is a reliable index for all five dimensions of service quality. First, the available components were rated in terms of patients expectations of quality of service in questionnaire A.

Then the same components were rated based on patients' perceptions of the actual quality of services provided in questionnaire B. Patient satisfaction was investigated using the third part of the questionnaire, the inpatient satisfaction questionnaire, which evaluated 9 dimensions, including measurement, reception and discharge services, medical services, nursing services, nutrition services, diagnostic and treatment services, welfare services, patient rights charter, accounting, insurance, and management services on a 5-point scale (5: Very satisfied, 4: Satisfied, 3: No idea, 
2: Dissatisfied, 1: Very dissatisfied). Questionnaire scores ranged from 45 to 225 .

In this study, the validity of the SERVQUAL questionnaire was determined based on concepts found in the scientific literature on the Parasuraman questionnaire and experts' opinions. The reliability of the Parasuraman questionnaire was determined using Cronbach a coefficient, and the perceptions and expectations dimensions rated 96\% and $93 \%$, respectively. In the current study, the Cronbach a coefficients of the used questionnaire were $87 \%$ and $85 \%$ for the dimensions of perceptions and expectations, respectively. The validity of the inpatient satisfaction questionnaire was approved by the Deputy of Treatment of Jondishapour University of Medical Sciences, and its Cronbach a coefficient was calculated to be $87 \%$. In the present study, the Cronbach a coefficient of the questionnaire was $83 \%$. (Nursing procedures for patients included a combination of planned educational activities to help individuals who are currently experiencing an illness or its complications. This program helps individuals make changes in their behavior until recovery is achieved.) The patient education program was not applied in the control group. The questionnaire was completed by both the experimental and the control group upon discharge from the relevant department.

To analyze the collected data, the raw data was first classified using the descriptive statistics and determined the percentage, mean, standard deviation, frequency distribution, and relative data. Then paired $t$ test, multivariable analysis of variance (ANOVA), chi-square, and Kolmogorov-Smirnov tests were used to test the hypotheses.

To enter the study setting, the researcher referred to the intended wards in different shifts according to a predetermined schedule and provided participants with sufficient information about the research objectives and their importance, maintaining anonymity, voluntary participation, and confidentiality of information (patients and nurses).

The questionnaire was made available to patients and nurses after obtaining a written consent letter, and the necessary explanations were given on how to complete it.

\section{Results}

Descriptive indicators of participants are reported for experimental and control groups in Table 1. The results of the descriptive indicators and the demographic characteristics show that the mean and standard deviation
Table 1. Demographic Characteristics and Comparison of Groups

\begin{tabular}{|c|c|c|c|}
\hline \multirow[t]{2}{*}{ Characteristics } & $\begin{array}{l}\text { Experimental } \\
\text { Group }\end{array}$ & $\begin{array}{l}\text { Control } \\
\text { Group }\end{array}$ & \multirow[t]{2}{*}{$P$} \\
\hline & No. $(\%)$ & No. $(\%)$ & \\
\hline Age & $32(100)$ & $32(100)$ & .788 \\
\hline Gender & & & .455 \\
\hline Female & $10(31)$ & $17(53)$ & \\
\hline Male & $22(69)$ & $15(47)$ & \\
\hline Marital status & & & .405 \\
\hline Single & $12(37.5)$ & $6(19)$ & \\
\hline Married & $20(63.5)$ & $26(81)$ & \\
\hline Level of education & & & 0.724 \\
\hline Illiterate & $24(75)$ & $24(75)$ & \\
\hline Less than diploma & $3(9)$ & $4(12.5)$ & \\
\hline Diploma & $3(9)$ & $4(12.5)$ & \\
\hline Higher & $2(7)$ & $0(0)$ & \\
\hline Insurance type & & & .632 \\
\hline Social security & $24(75)$ & $23(72)$ & \\
\hline Health service & $5(16)$ & $5(16)$ & \\
\hline Armed forces & $0(0)$ & $1(3)$ & \\
\hline Other & $3(9)$ & $3(9)$ & \\
\hline
\end{tabular}

of age for the experimental and control groups were (40.03, $15.71)$ and $(39.06,12.80)$, respectively.

The results of independent $t$ tests showed that there is no significant difference between the two groups in terms of age $(P=.788, t(32)=0.191)$. The results of the chi-square test showed that there is no significant difference between the experimental and control groups in terms of education level $(P=.724)$ or gender variables $(P=.475)$. Thus, it can be concluded that the random assignment of subjects to the experimental and control groups homogenized the two groups in terms of demographic variables.

The results of mean and standard deviations of scores for quality of nursing care and inpatient satisfaction in the experimental and control groups on both the pre-test and post-test are shown in Table 2.

In the present study, the null hypothesis is that there is no gap between the perceived and expected quality of service. The results are shown in Table 3. The normal distribution of observations was first studied using the Kolmogorov-Smirnov test. Then, data was analyzed using parametric independent $t$ test to compare the averages. The experimental group had a significance level of higher

Table 2. Mean and Standard Deviations of Pre-test and Post-test Scores for Quality of Nursing Care and Inpatient Satisfaction in the Experimental and Control Groups

\begin{tabular}{|c|c|c|c|c|c|}
\hline \multirow{2}{*}{ Variables } & \multirow{2}{*}{ Groups } & \multicolumn{2}{|c|}{ Experimental } & \multicolumn{2}{|c|}{ Control } \\
\hline & & Pre-test & Post-test & Pre-test & Post-test \\
\hline \multirow{2}{*}{ Quality of nursing care } & Mean & 33.8 & 38.55 & 37.30 & 35.20 \\
\hline & SD & 7.6 & 5.78 & 6.16 & 6.86 \\
\hline \multirow{2}{*}{ Quality of nursing care } & Mean & 47.67 & 55.58 & 52.80 & 51.87 \\
\hline & SD & 8.29 & 4.96 & 5.97 & 6.22 \\
\hline
\end{tabular}


Table 3. Results of Gap Analysis in Quality of Nursing Care

\begin{tabular}{|c|c|c|c|c|c|c|c|c|}
\hline & \multirow{3}{*}{ Mean } & \multicolumn{4}{|c|}{ Paired Differences } & \multirow{3}{*}{$t$} & \multirow{3}{*}{$d f$} & \multirow{3}{*}{$\boldsymbol{P}$} \\
\hline & & \multirow{2}{*}{ Standard Deviation Mean } & \multirow{2}{*}{ Standard Deviation } & \multicolumn{2}{|c|}{ Confidence Level } & & & \\
\hline & & & & Low & High & & & \\
\hline Experimental group & 1.27318 & 0.05196 & 0.05196 & 1.16513 & 1.38124 & 20.504 & 31 & .236 \\
\hline Control group & 1.62108 & 0.04369 & 0.04369 & 1.61002 & 1.23245 & 22.321 & 31 & .000 \\
\hline
\end{tabular}

Table 4. Summary of Analysis Results for Covariance of the Comparison Between the Average/Mean Grades/Marks of Quality of Nursing Services and the Hospitalized Patients' Satisfaction

\begin{tabular}{|c|c|c|c|c|c|c|c|}
\hline Dependent variable & Source & Sum of Squares & Mean Square & $F$ & $P$ & Effect Size & Power \\
\hline \multirow{3}{*}{$\begin{array}{l}\text { Quality of nursing } \\
\text { care }\end{array}$} & Group & 261.09 & 261.09 & 15.907 & .001 & 0.399 & 0.969 \\
\hline & Pre-test & 418.725 & 418.725 & 25.511 & .001 & 0.515 & 0.998 \\
\hline & Error & 393.925 & 16.414 & & & & \\
\hline \multirow{3}{*}{$\begin{array}{l}\text { Inpatients' level of } \\
\text { satisfaction }\end{array}$} & Group & 588.223 & 588.223 & 25.582 & .001 & 0.516 & 0.998 \\
\hline & Pre-test & 3934.409 & 3934.409 & 171.111 & .001 & 0.887 & 1.000 \\
\hline & Error & 551.941 & 22.933 & & & & \\
\hline
\end{tabular}

than .05 , which indicated that the null hypothesis was confirmed.

A significant difference was found between pre-test and post-test scores for the quality of nursing care. There was a statistically significant difference between the control and experimental groups in the adjusted mean scores of the quality of nursing care at post-test (after controlling pre-test scores $)(P=.001)$. The results are shown in Table 4 . Thus, this hypothesis is confirmed. In other words, patient education increased the quality of nursing care for patients hospitalized in the surgical department in the post-test phase. The effect size of this education in enhancing the quality of nursing care in the post-test was 0.399 ; i.e. about $39.9 \%$ of the variance in quality of nursing care was related to the effect of education. A statistical power of $96 \%$ shows that the statistical precision of this test is high; moreover, the sample size was adequate for testing this hypothesis.

A significant difference was also seen between pretest and post-test inpatient satisfaction scores. There was a significant difference between the control and experimental groups in the adjusted average inpatient satisfaction scores at post-test (after controlling for pre-test scores) $(P=.001)$; thus, the hypothesis was confirmed. In other words, patient education increased inpatient satisfaction in the surgical department at the post-test phase.

The size of education effect in increasing inpatient satisfaction in the post-test was 0.516 ; i.e. about $51.6 \%$ of the variance in patient satisfaction is related to the effect of education or group. Statistical power of $99 \%$ shows that the statistical precision of this test is high; moreover, the sample size was adequate to test this hypothesis.

\section{Discussion}

The findings of this study showed that there is no gap between expected quality and perceived quality of nursing services in the experimental group. Patients' expectations and their perception of the present situation have been satisfied using the patient education program. Patient education also increased the quality of nursing care and patient satisfaction; therefore, it is an important issue in the provision of health services by an organization. It is also considered the most basic and vital of issues in healthcare systems and is the most significant duty of all health professionals. ${ }^{20}$

Patient education is effective as a part of nursing care when its implementation reduces costs, length of hospitalization, and patient's anxiety and increases patients' satisfaction with the provided healthcare services. ${ }^{21}$ Bastable suggested that patient education can increase patients' satisfaction, improve service quality, reduce patients' anxiety, reduce complications, increase participation in healthcare programs, and increase patients' independence in daily activities, which is consistent with the results of the present study. ${ }^{22}$ Furthermore, studies conducted by Nouhi AS, Pooraboly, ${ }^{15}$ Zimmer et al, ${ }^{17}$ and $\mathrm{Du}$ et $\mathrm{al}^{18}$ achieved results that are somewhat consistent with those of the present study, which reflects patient desire to receive patient education and nursing care. Various studies on patient education have also been conducted in Iran. In a study on the effect of nursing education on inpatient satisfaction, Mahdipour et $\mathrm{al}^{23}$ showed that there are significant differences between patients' mean satisfaction scores before and after the intervention. In a study on the effect of patient education and telephone follow-up by nurses, Shojaee et $\mathrm{al}^{24}$ stated that this lowcost intervention significantly increased patients' level of hope after discharge. Also, although nurses and other healthcare staff members considered patient education to be one of their critical duties, patients still believed that they are not provided with the necessary education. If nurses improve their awareness of the importance of this education, their performance will be improved; therefore, patient satisfaction and patients' quality of life and level of hope will ultimately be improved.

\section{Conclusion}

The results of the present study indicate the importance of the educational role of nurses and nursing managers 
and emphasis this role as part of their nursing duties in increasing the quality of services and patient satisfaction. However, it seems that a heavy workload and large number of patients cause nurses to pay less attention to their educational role. Managers should adopt necessary planning strategies to implement this important goal and motivate nurses. They should also consider active participation in improving patient satisfaction as a hospital management priority. It should be noted that in today's competitive market, only those institutions that pay more attention to patient satisfaction by increasing the quality of care and pay attention and focus their activities on methods that are meant to improve the quality of care will be most successful.

The limitations of this study include the lack of generalizability of the results to other wards and differences in patient education by nurses. As the present study was focused only on the effect of an education program on patients hospitalized in the surgical ward, other strategic wards such as emergency and inpatient wards were not studied. Because the conditions of patients in these wards differ from those of patients admitted to the surgical ward, it is recommended that further research be conducted on the effect of patient education programs on the quality of nursing care and patient satisfaction in these wards.

\section{Authors' Contributions}

All authors contributed equally to this research.

\section{Conflict of Interest Disclosures}

None.

\section{Ethical Approval}

This study was approved by the Ethics Committee of Isfahan University of Medical Science; all necessary permissions were obtained from the relevant authorities prior to beginning the study.

\section{Acknowledgments}

The present research project was approved by the Vice Chancellor of Research of Isfahan University of Medical Sciences which undertook the financial support of the center. The authors hereby express their gratitude to the staffs of Shahid Ayatollah Sadoughi, Sina, and Ayatollah Kashani hospitals, especially those people participating in the research, for their sincere cooperation.

\section{References}

1. Walling AM, Maliski S, Bogorad A, Litwin MS. Assessment of content completeness and accuracy of prostate cancer patient education material. Patient Educ Couns. 2004;54(3):337-343. doi:10.1016/j.pec.2003.10.005.

2. Tolooee M, Dehghan Nayery N, Faghihzadeh S, Sadooqi-Asl A. Motivational factors for nurses with patient education. Hayat. 2006;2(12):43-45. [Persian].

3. Purraberi M, Jamshidi N, Soltani Nejad A, Sabzevari S. The impact of nursing on patient satisfaction and patient education on knowledge, attitude and practice of cardiac intensive care unit nurse. Journal of Health and Care. 2011;13(1):30-36. [Persian].

4. Mobaraki A, Karimi Z. Importance of patient education from

\section{Research Highlights}

\section{What Is Already Known?}

Although prior to this study the importance of patient education was recognized, it was not taken seriously. Studies were unsystematic, and patient satisfaction and quality of nursing care were not evaluated..

\section{What This Study Adds?}

Results of the current study indicate that, despite their heavy workload, nurses should attend to, strengthen, and consider as a supplement to nursing care patient education activities. Moreover, related educational courses should be planned in order to better implement patient education programs. Senior managers should provide adequate support in this regard.

the perspective of nursing students. Dena.2006;3(1):61-68. [Persian]

5. Salehi A. A survey of educational needs in health-therapeutic centers of Isfahan in 2005. Regional Seminar on New Methods of Patients Care and Education. Ahvaz: Islamic Azad University. Ahvaz Branch; 2005. [Persian].

6. Rankin SH, Stallings KD, London F, eds. Patient Education in Health and Illness. Philadelphia, PA: Lippincott Williams and Wilkins; 2005.

7. Berwick D. Postgraduate education of physicians: professional self-regulation and external accountability. JAMA. 2015; 313(18):1803-4. doi:10.1001/jama.2015.4048.

8. Bastable SB, Gramet P, Jacobs K, Sopczyk D. Health Professional as Educator: Principles of Teaching and Learning. UK: Jones \& Bartlett learning; 2011.

9. Cardiovascular disease statistics. American Heart Association website. http://www.americanheart.org/downloadable/ heart/1105390918119HDSStats.

10. Lewis SL, Bucher L, Dirksen SR, Heitkemper MM. Medical Surgical Nursing: Assessment and Management of Clinical Problems. Elsevier; 2011:49-50.

11. Arian M. The effect of designed walking program with holistic nursing approach on serum ferritin and heart problems of thalassemia major patients [Thesis]. Tehran: Tarbiat Modares University; 2013. [Persian].

12. Emami Razavi H, Mohaghegh MR, Razavi S. Accreditation standards for hospitals in Iran. Tehran: Sound Publishing Center; 2010:73-80. [Persian].

13. Hakari D, Mohamadzadeh R. Survey the status of patient education in nursing students and nurses and its effective factors in Tabriz hospitals in 86-87. Medical Science Journal of Islamic Azad University. 2010;20(1):58-63. [Persian].

14. Bahrampour A, Zolala F. Patient satisfaction and related factors in Kerman hospitals. East Mediterr Health J. 2005;11:905-912. [Persian].

15. Nouhi AS, Pooraboly B. Educational requirements of the discharged patients and their satisfaction about nursing educational performance, Kerman, Iran. Hormozgan Med J 2009;13(3):206-212. [Persian].

16. Taylor N. A Patient education program supported by staff training can reduce the rate of falls for older patients during inpatient rehabilitation. J Physiother. 2015;61(4):224. doi:10.1016/j.jphys.2015.07.016.

17. Zimmer A, Blauer C, Coslvosky M, Kappos L, Derfuss T. Optimizing treatment initiation: effects of a patient education program about fingolimod treatment on knowledge, selfefficacy and patient satisfaction. Mult Scler Relate Disord. 2015;4(5):444-450. doi:10.1016/j.msard.2015.06.010.

18. Du S, Hu L, Dong J, Xu G, Jin S, Zhang H, Yin H. Patient education programs for cancer - related fatigue: a systematic 
review. Patient Educ Couns. 2015;98(11):1308-1319. doi:10.1016/j.pec.2015.05.003.

19. Coates VE. Education for Patient and Client. London: Routledge; 1999.

20. Redman BK. The Practice of Patient Education. 8th ed. New York: Mosby; 2001.

21. Krupat E, Fancey M, Cleary PD. Information and its impact on satisfaction among surgical patients. Soc Sci Med. 2000; 51(12):1817-25. doi:10.1016/s0277-9536(00)00113-1.

22. Bastable SB, ed. Nurse as Educator: Principles of Teaching and
Learning for Nursing Practice. Boston: Jones and Bartlett; 2003

23. Mehdipour R, Jamshidi N, Soltani Nejad A, Sabzevari S. Effects of nurse education on both patients' satisfaction of teaching patients, and nurses' knowledge, attitude and performance in intensive care units of teaching hospitals. Journal of Health and Care. 2011;13(1):29-36. [Persian].

24. Shojaee A, Tahrir B, Naderi N, Zareian A. Effect of patient education and telephone follow up by the nurse on the level of hope in patients suffering from heart failure. JNE. 2013;2(1):1626. [Persian]. 